\title{
QUALIDADE DA EDUCAÇÃO CIENTÍFICA NA VOZ DOS PROFESSORES *
}

\section{Quality of Science Education in teachers' voice}

\author{
Flavia Rezende ${ }^{1}$ \\ Márcia Sampaio Duarte ${ }^{2}$ \\ Luziane Beyruth Schwartz ${ }^{3}$ \\ Roberta Comissanha de Carvalho ${ }^{4}$
}

\begin{abstract}
Resumo: O objetivo desta pesquisa foi investigar os sentidos de qualidade atribuídos por professores do Ensino Médio ao ensino de ciências. O estudo baseia-se em um grupo focal realizado com nove professores das ciências naturais e de matemática de escolas públicas e privadas da cidade do Rio de Janeiro. A análise do discurso dos professores baseou-se na perspectiva sociocultural de Wertsch, que integra os conceitos fundamentais da filosofia da linguagem de Bakhtin. Inventariamos perspectivas de qualidade presentes nos discursos dos professores e seu diálogo com diferentes linguagens sociais. Apesar das diferenças entre contextos educacionais e linguagens sociais usadas pelos professores, percebemos um sentido negativo de qualidade atribuído por todos eles à educação científica. Assim, os professores enunciam o que seria a suposta qualidade por meio do discurso sobre sua falta. Identificamos tensões que problematizam suas perspectivas de qualidade acerca do currículo, do trabalho docente, da aprendizagem, das tecnologias e da legislação educacional.
\end{abstract}

Palavras-chave: Ensino de ciências. Professores. Análise do discurso. Qualidade de ensino.

\begin{abstract}
The purpose of this study was to investigate the meanings of quality attributed by secondary teachers to science education. The study was based in a focal group with nine science teachers from public and private schools of Rio de Janeiro. The discourse analysis was oriented by Wertsch's sociocultural perspective, which integrates the fundamental concepts of Bakhtin's philosophy of language. An inventory of the perspectives on quality in the teachers' discourse was done and their dialogue with different social languages. Despite the differences between educational contexts and between the social languages used by the teachers, we can point to the recurrent meaning of lack of quality, attributed by all the teachers to scientific education. Thus, teachers enunciate what the supposed quality would be through a discourse on its lack. We identified tensions that problematize the perspectives of quality related to curriculum, teachers' work, learning, technologies and educational policies.
\end{abstract}

Keywords: Science education; Teachers; Discourse analysis. Quality of teaching.

\footnotetext{
${ }^{*}$ Com apoio do Edital Observatório da Educação - Capes.

${ }^{1}$ Licenciada em Física,doutora em Educação. Docente, Núcleo de Tecnologia Educacional para a Saúde, Universidade Federal do Rio de Janeiro (UFRJ), RJ, Brasil. <flaviarezende@uol.com.br>

${ }^{2}$ Graduada em Educação Física, doutoranda em Educação em Ciências e Saúde, UFRJ, RJ, Brasil.

<sampaioduarte@oi.com.br>

${ }^{3}$ Licenciada em Matemática, doutoranda em Educação em Ciências e Saúde, UFRJ, RJ, Brasil. <luzianebs@gmail.com>

${ }^{4}$ Graduada em Educação Física, mestranda em Educação em Ciências e Saúde, UFRJ, RJ, Brasil.

$<$ comissanha@hotmail.com>

${ }^{1}$ Centro de Ciências da Saúde, Bloco A - sala 12

Av. Carlos Chagas Filho, 373

Cidade Universitária - Rio de Janeiro, RJ

21.941-902

269

Ciência \&̊E Educação, v. 17, n. 2, p. 269-288, 2011
} 


\section{Qualidade e Educação em Ciências}

A história da pesquisa em ensino de ciências pode nos ajudar a entender como têm sido postas questões sobre a sua qualidade. Sua origem na América do Norte, como consequência dos esforços empreendidos para aumentar a eficiência do ensino de ciências frente à corrida espacial na década de 50 do século XX, marca até hoje, com traços do eficienticismo pretendido naquele momento, tanto a pesquisa quanto o ensino nessa área. Desde então, a pesquisa em Educação em Ciências ${ }^{5}$ (EC) tem priorizado os aspectos metodológicos e epistemológicos e a consideração à lógica do conhecimento científico de referência, no sentido de garantir a eficiência dos processos de ensino-aprendizagem. Esta característica, ainda dominante, assume a qualidade do ensino de ciências enquanto qualidade do processo educativo sem ver como necessária a reflexão sobre seus objetivos, assumindo-os como evidentes ou como a formação de quadros técnicos necessários ao desenvolvimento científico e tecnológico e ao mercado. Esta falta de questionamento dos objetivos da EC parece desconsiderar a educação como campo intrinsecamente político e social, o que, por conseguinte, deixa a discussão sobre qualidade passar ao largo desses aspectos.

É possível ver essa tendência na área de física, por ter sido esta área, entre as ciências naturais, a precursora no desenvolvimento de pesquisas em ensino. De acordo com o mapeamento recentemente realizado por Rezende, Ostermann e Ferraz (2009), o estado da arte da produção nacional sobre o ensino de física concentra-se na temática ensino-aprendizagem, apoiando-se sobre um tripé: propostas de metodologias e estratégias de ensino, desenvolvimento de experimentos para o laboratório didático e elaboração de recursos didáticos para a sala de aula. As autoras interpretam essa configuração da área como "a expressão de uma visão instrumentalista da pesquisa em ensino e muitas vezes tecnicista do processo educativo, que visa basicamente ao fornecimento de subsídios ao professor para melhorar o desempenho do aluno" (REZENDE; OSTERMANN; FERRAZ, 2009, p. 5).

Considerando que, assim como a física, as áreas de biologia, química e matemática tenham priorizado o desenvolvimento e a pesquisa das dimensões metodológicas e epistemológicas do ensino, é possível vislumbrar que a produção já alcançou um nível de conhecimento importante no sentido de indicar direcionamentos para a qualidade da prática docente e da aprendizagem como, entre outros: a necessidade de se considerar o conhecimento prévio do aluno, a necessidade de se mudar a crença epistemológica empirista impressa no ensino de ciências, a necessidade de se fomentarem interações dialógicas e caminhos para incorporação das tecnologias da informação e comunicação (TIC) no ensino.

Por outro lado, a área de EC tem dado pouca importância às políticas educacionais como caminho para se atingir a qualidade. Ainda que pesquisadores da área tenham se envolvido com a elaboração dos Parâmetros Curriculares Nacionais do Ensino Médio (PCNEM) no final da década de 1990, é notável que, nos eventos da área, o número de trabalhos sobre

\footnotetext{
${ }^{5}$ Ao longo do texto, mantivemos as expressões ensino de ciências e educação em ciências, entendendo que a primeira é mais identificada com a linguagem escolar e a segunda com o meio acadêmico. 
essa temática tem sido frequentemente muito baixo ou até nulo. Talvez justamente a falta de reflexão tenha como consequência o fato de que, em muitas pesquisas da área, diretrizes destes documentos são citadas para validar ou justificar o trabalho ou são até usadas como referencial teórico da pesquisa. É possível perceber que a produção acadêmica da área de EC se volta para o atendimento e divulgação das propostas curriculares oficiais (REZENDE; OSTERMANN, 2005).

Sendo os PCNEM (BRASIL, 1998) para a área de ciências naturais construídos a partir dos conceitos de interdisciplinaridade, competências e contextualização, é possível inferir que a pesquisa tem assumido estes conceitos como sinônimos de qualidade. Entretanto, críticas aos PCNEM trazem à tona objetivos educacionais que são valorizados a partir dos conceitos metodológicos dessa proposta. Por meio dos conceitos de contextualização e competências, seria difundida a ideia de que a educação deve servir de ferramenta de inserção social, vinculando-se ao mundo produtivo, sem se preocupar com os questionamentos de como se constituiu ou se constitui este mundo. Como consequência, tem-se observado que muitos professores entendem o princípio da contextualização como sinônimo de abordagem de situações do cotidiano, no sentido de descrever os fenômenos da natureza com a linguagem científica, deixando de explorar as dimensões sociais, políticas e culturais nas quais esses fenômenos estão inseridos (SANTOS, 2007a).

Entendemos que, embora toda a produção da área dedicada ao processo de ensinoaprendizagem possa ser considerada um passo importante na direção da qualidade, não há como desvincular a reflexão sobre a qualidade do ensino de ciências da reflexão sobre seus objetivos. Chassot (1998), por exemplo, alerta para o fato de que, sendo a educação um processo político e ideológico, a educação científica poderá tanto preparar o indivíduo para a utilização racional do conhecimento científico e tecnológico para buscar o bem da coletividade, como para explorar o conhecimento apenas a fim de obter benefícios pessoais, independente das consequências sociais e ambientais de tal atitude.

Lemke (2006) defende a reorientação do currículo de ciências para questões e problemas sociais que terão de ser enfrentados por toda a humanidade no século XXI, como: a crise ambiental, a injustiça social e a opressão e injustiça invisíveis para com os mais jovens visando a uma sociedade melhor e uma vida mais satisfatória para as pessoas. O autor acredita que legisladores e protagonistas da EC devem tomar atitudes políticas e morais ou seremos julgados, seja pelos estudantes, seja pela história, como socialmente irresponsáveis.

Esta orientação está longe de ser realizada, apesar de defendida, atualmente, por alguns pesquisadores, como Banet (2007), para quem é evidente que a formação recebida pelos estudantes no Ensino Secundário, centrada nos conceitos e leis próprios das disciplinas, não atende às necessidades da sociedade atual e deixa de lado outros âmbitos formativos importantes, como os processos que caracterizam a atividade científica. Assim, nem se efetiva uma EC satisfatória, nem se atendem às necessidades formativas dos cidadãos na atualidade.

Os estudos sobre as abordagens curriculares com ênfase na relação Ciência-Tecnologia-Sociedade (CTS) são a linha de pesquisa da área que prioriza a qualidade política da ciência e da educação. Estes estudos defendem um currículo que explore a relação entre Ciência, Tecnologia e Sociedade, e apontam, como sua principal proposta, a preparação dos estudantes para o exercício da cidadania (SANTOS; MORTIMER, 2002). Estes autores alertam, por outro lado, que uma reforma curricular com ênfase em CTS implica mudanças de concepções 
do papel da educação e da EC, ou estaremos incidindo no erro de, simplesmente, maquiar os currículos atuais com pequenas aplicações de temas sociais do cotidiano.

Moreira e Kramer (2007) trazem as ideias de Avalos sobre a concepção de qualidade da educação centrada na realidade do Terceiro Mundo, ao considerar como conhecimento escolar apropriado aquele que possibilita ao estudante tanto um bom desempenho no mundo imediato quanto a análise e a transcendência de seu universo cultural. Para os autores, relevância da educação diz respeito "ao potencial que certos conhecimentos e processos pedagógicos apresentam de tornar as pessoas aptas a definir o papel que devem ter na mudança de seus ambientes e no desenvolvimento da sociedade" (MOREIRA; KRAMER, 2007, p. 1045).

Diante das diversas possibilidades de se correlacionar o ensino de ciências com concepções de qualidade da educação, e da necessidade de se avançar nesta discussão, consideramos importante trazer, para o debate, os reais protagonistas do cenário educacional, procurando compreender como professores das ciências de diferentes realidades educacionais e das diferentes disciplinas científicas constroem discursos sobre as políticas educacionais, a ciência, o currículo, a avaliação, os objetivos educacionais, e como relacionam estes discursos à qualidade da EC que realizam ou sonham realizar.

\section{Quadro teórico-metodológico}

A perspectiva sociocultural (WERTSCH, 1993) parece adequada para problematizar a questão da "qualidade", tendo em vista a natureza polissêmica dessa palavra e quanto a mesma depende da atribuição de sentidos pelos sujeitos. Ao propor a aproximação à ação humana a partir dos gêneros discursivos (BAKHTIN, 2003) como instrumentos mediadores, Wertsch (1993) estabelece diálogo com constructos analíticos que possam ir além dos cenários psicológicos, expandindo-se para as ciências sociais e ciências humanas. Assim como Vygotsky, Bakhtin (2004) buscou compreender as questões epistemológicas das ciências humanas e sociais, considerando a linguagem como elemento organizador da vida mental e fundamental na formação do sujeito histórico-social. Daí o valor que atribuiu à palavra e à interação com o outro. Para ambos, o conhecimento é uma construção social mediada pelo outro, através da linguagem (FREITAS, 2003). No entanto, a linguagem, para esses autores, não é apenas um veículo de transmissão de conteúdo, mas possui uma dimensão constitutiva de formas de pensar e significar. Para eles, é na interação entre sujeitos, mediada pelo discurso e no discurso, que ocorre a elaboração do conhecimento.

$\mathrm{Na}$ contramão das grandes correntes teóricas da linguística, que predominavam até então, Bakhtin (2004) considerou, o enunciado, expressão e produto da interação social, como a verdadeira unidade de análise da comunicação verbal. O enunciado reflete, além da voz que o produz, as vozes a quem se dirige (WERTSCH, 1993). O conceito de voz em Bakhtin (2003) não se refere a sinais auditivo-vocais, mas envolve questões mais amplas da perspectiva do sujeito falante, seu horizonte social, sua intenção e sua visão de mundo. Este conceito enfatiza o pressuposto bakhtiniano de que a atividade mental a exprimir, a estrutura da enunciação e sua elaboração estilística são de natureza sociológica (BAKHTIN, 2004).

Para analisar as enunciações buscando a construção de sentido, é preciso recorrer à noção de dialogia, conceito-chave em Bakhtin (2004), que pressupõe que, em todo enunciado, 
há, pelo menos, duas vozes, mesmo que não haja interação face a face. Quando um sujeito fala, o faz referente a algo ou a outra voz. Mesmo que um enunciado não esteja respondendo de alguma maneira a enunciados anteriores, ele antecipa as respostas de outros enunciados que se seguirão. O interesse de Bakhtin (2004) pela direcionalidade do enunciado envolve tanto o interesse por quem produz o enunciado como a quem esse enunciado é dirigido. Nesse sentido, o ato de compreender não é apenas decodificar um conteúdo, mas requer do interlocutor uma ação ativa e reativa, porque "para cada palavra da enunciação que estamos em processo de compreender, fazemos corresponder uma série de palavras nossas, formando uma réplica" (BAKHTIN, 2004, p. 132). Quanto maior o número e o peso dessas palavras, mais profundo e substancial será nosso entendimento.

Os enunciados e os significados dos enunciados estão intrinsecamente inseridos num contexto sociocultural e, por isso, são permeados de influências socioculturais: pela direcionalidade dos enunciados (para quem falamos ou a quem nos referimos), pelo contexto em que esses enunciados são produzidos (na escola, em casa) e pela função que esses enunciados desempenham (uma petição, uma carta pessoal). Bakhtin (2003) abordou a situacionalidade do enunciado no conceito de gênero discursivo. O gênero discursivo é, assim, um tipo de enunciado que se caracteriza em função de situações típicas de comunicação verbal, ao contrário da linguagem social, que é um tipo social de fala associado a um extrato específico da sociedade (segundo profissão, faixa etária etc.). Logo, a produção de todo enunciado implica a apropriação de, pelo menos, uma linguagem social e um gênero discursivo, porque esses tipos sociais de fala estão situados socioculturalmente (WERSTCH, 1993). Para Bakhtin (2003), a enunciação é de natureza social, portanto, ideológica, e não existe fora de um contexto social. Assim, a forma linguística é sempre mutável: "a entonação expressiva, a modalidade apreciativa sem a qual não haveria enunciação, o conteúdo ideológico, o relacionamento com uma situação social determinada, afetam a enunciação" (JACOBSON apud BAKHTIN, 2004, p. 16).

A resposta à pergunta "quem está realizando o ato da fala?" (Wertsch, 1993, p. 83) implica, do ponto de vista bakhtiniano, sempre, pelo menos, duas vozes, o que acentua a produção do significado, não no indivíduo isolado, mas na vida grupal. A compreensão de como as linguagens sociais e gêneros discursivos se relacionam na composição dos enunciados é indispensável para a análise de como diferentes vozes se põem em contato.

Uma possibilidade de composição de um enunciado é por meio da apropriação de discursos. Mais especificamente, o que define apropriação é a ação que vai além do contato com outras vozes ou com outros discursos, é "trazer algo para o interior de si mesmo e fazê-lo próprio" (WERTSCH, 1999, p. 92). Apropriar-se do discurso é, em parte, tornar suas as palavras do outro, lhes acrescentando intenção semântica e expressividade próprias, dando voz a sua manifestação discursiva e promovendo sua reconstrução. Por este processo, o sujeito amplia o domínio de um discurso, incorporando novos horizontes de compreensão e de participação.

Neste processo, Bakhtin (2003) chama atenção para a relação do falante com o enunciado e com outros participantes da comunicação verbal. Em relação à primeira "conformação", os aspectos mais importantes são o conteúdo semântico referencial e o aspecto expressivo do sujeito que, para Wertsch (1993), pode ser estendido à ideia de perspectiva ou de ponto de vista sobre o conteúdo do enunciado.

O conceito de dialogia responde pela relação entre o falante e o enunciado de outros. Assim, fazer uso da linguagem requer apropriar-se das palavras do outro e torná-las, em parte, 
Rezende, F. et al.

nossas. Isso porque não existe uma linguagem neutra e impessoal, disponível para ser usada, mas para torná-la própria é preciso tomá-la dos contextos e das intenções dos outros. A partir destes processos dialógicos é possível encontrar diferenças entre os enunciados de uma linguagem social e os de outra (WERTSCH, 1993).

No presente estudo, tomamos os conceitos fundamentais da perspectiva sociocultural de Wertsch (1993) para analisar as enunciações de professores de ciências naturais e de matemática participantes de um grupo focal que teve como objetivo a discussão sobre a qualidade do ensino de ciências.

\section{Descrição do grupo focal}

Realizamos um grupo focal com nove professores, uma mediadora, dois pesquisadores responsáveis pela gravação em vídeo e dois relatores, em uma universidade do Rio de Janeiro, com duração de aproximadamente duas horas. O grupo de professores incluiu: um professor de química de uma escola privada (Paulo); um professor de química de uma escola prisional, uma escola pública e uma privada (Júlio); um professor de matemática de uma escola pública (Ronaldo); um professor de física de uma escola pública (Marcelo); uma professora de física de uma escola particular (Gabriela); uma professora de química de uma escola técnica pública (Fátima); uma professora de matemática de uma escola pública (Tatiana); um professor de biologia de uma escola pública (César) e uma professora de biologia de uma escola pública de formação de professores (Ana).

De início, a mediadora esclareceu que a atividade era parte de um projeto de pesquisa, no âmbito do edital Observatório da Educação da CAPES, sobre a qualidade da EC no Ensino Médio (EM). Em seguida, cada professor se apresentou ao grupo, descrevendo um breve currículo e seu local de trabalho. A mediadora convidou-os, então, em um primeiro momento, a exporem o que pensavam sobre o ensino de ciências que praticavam em sua escola (questões relacionadas ao ensino e à aprendizagem, ao currículo, à avaliação, aos objetivos educacionais e outras). Em seguida, a mediadora questionou os professores acerca do que acreditavam ser um ensino de ciências e matemática de qualidade, o que os fez debater mais especificamente sobre este novo tema.

\section{Procedimentos de análise}

Com base na transcrição da gravação em vídeo, analisamos o discurso de todos os professores após o momento de apresentação. Esta análise pretendeu identificar os sentidos de qualidade da EC nos enunciados dos professores, considerados como sua fala ou turno, ou seja, cada vez que os professores se dirigiam à mediadora ou ao grupo. Como a mediadora sugeriu inicialmente um tema amplo e, em seguida, o debate sobre a qualidade, que, como já vimos anteriormente, é uma palavra de caráter polissêmico, os professores acabaram elegendo temas diversos em ambos os momentos da atividade. Por meio de enunciados longos, abordaram, em geral, mais de um tema, que consideramos como subtemas dos temas mais amplos. 
A primeira etapa da análise foi identificar os subtemas que compunham o conteúdo semântico referencial dos enunciados dos professores. Após esta etapa, partimos para a análise da relação do falante com seu enunciado, ou seja, a identificação das vozes dos professores, considerando-as como perspectivas referenciais (WERTSCH, 1993) sobre aquele(s) subtema(s). Para identificá-las, inferimos qual era o ponto de vista do falante, como e por que o tema foi relacionado com qualidade. Ainda que não aparecesse a palavra qualidade nas falas dos professores, buscamos identificar a posição valorativa dos professores frente àquele subtema relacionado ao ensino de Ciências e Matemática, bem como à educação stricto sensu.

$\mathrm{Na}$ interpretação das perspectivas dos professores, levamos em consideração tanto a situação atual de enunciação e, portanto, a direcionalidade dos enunciados (os professores falavam para outros professores e pesquisadores como parte de uma atividade acadêmica) quanto aspectos de sua formação e do contexto educacional e sociocultural específico ao qual o professor se reportava. Estes aspectos nos ajudaram a identificar as linguagens sociais com as quais eles dialogavam para exprimir suas vozes.

\section{Perspectivas dos professores sobre qualidade da educação científica}

Embora conscientes da complexidade do fenômeno educativo e de quanto é impossível vê-lo como uma soma de aspectos isolados, identificamos, de um lado, enunciados contextualizados na realidade escolar - abordando os alunos, a aprendizagem, o currículo, o trabalho docente, a formação do professor, as tecnologias e a escola - e, de outro, enunciados sobre a realidade mais ampla, relativos à legislação educacional e às finalidades políticas da educação. Em cada uma dessas dimensões, buscamos descrever o máximo de perspectivas enunciadas pelos professores, compondo um inventário de vozes docentes sobre a qualidade da educação científica, e, especificamente, sobre cada subtema abordado por eles. Os nomes dos professores são fictícios e os enunciados reproduzidos ao longo da análise foram colocados entre aspas.

\section{Aprendizagem: falta de base, de interesse, de prazer}

Paulo, que trabalha numa escola tradicional privada, do $9^{\circ}$ ano ao EM, relata sua dificuldade de aprofundar o ensino da química básica devido à defasagem de conteúdos com que seus alunos chegam ao EM e às dificuldades de interpretação e de raciocínio, atribuindo à ausência de pré-requisitos dos alunos a falta de qualidade do seu ensino:

\section{"Então o problema é o que? É o professor? É a aula? E até que você chega: não mãe, o problema todo é o nivel. Os alunos estão chegando muito mal preparados no EM'.}

Fátima relata que sua experiência é diferente da dos demais professores no que se refere à reprovação e ao interesse dos alunos pelas ciências, por trabalhar em uma escola técnica federal, onde o ensino de ciências, sobretudo das disciplinas de física, química e matemática, compõe a base do curso técnico. Ao mesmo tempo, reiterando a fala de Paulo, Fátima 
considera que, mesmo os alunos tendo ingressado através de um processo seletivo rigoroso, também têm dificuldades para escrever e pensar logicamente. Outro aspecto abordado por Fátima é de natureza comportamental, quando ela julga os alunos de hoje mais inquietos, rebeldes e sem respeito à hierarquia, reflexo dos problemas familiares com os quais estes alunos convivem na atualidade.

Gabriela acredita que a educação dos dias de hoje reflete uma característica que, segundo ela, faz parte da sociedade atual: "o prazer a qualquer custo é o mais importante, você sentir o praz̧er em tudo o que você faz, nada tem que ser por obrigação", mas reconhece que "nem tudo tem que ser imediato; às vezes, nem o professor sabe para que vai servir aquilo para o aluno, pode ser que um dia sirva, pode ser que não", mas ele tem precisa ter "a consciência de que o aluno tem que aprender algumas coisas porque tem que ser assim; algumas coisas têm explicação, outras, não".

Ana situa o contexto atual, onde as novas configurações psíquicas dos jovens exigem atividades mais dinâmicas e multimidiáticas, talvez por influência da velocidade e multiplicidade de meios presentes nas mídias. Em contrapartida, na escola, há entraves burocráticos ou de infraestrutura quando os professores querem utilizar recursos tecnológicos ou usar espaços diferentes da sala de aula. Com a ausência de recursos para uma aula mais prazerosa, esbarrase em aulas tradicionais nas quais o aluno tem de aprender "sem prazer". Ainda assim, Ana contrapõe-se à concepção de Gabriela, defendendo que a responsabilidade pelo prazer na aprendizagem é uma via de mão dupla na qual também cabe ao aluno certo esforço:

"o aluno também tem que entender que a gente vai fazer o que for possível, mas
têm coisas que são doídas e sofridas como tudo na vida. Não dá pra gente também
endeusar e dizer que a gente só aprende com prazer não. A gente aprende sem
prazer".

Concordando com a posição de Fátima, Ronaldo aponta que o aluno "tem que aprender mesmo". Trazendo a discussão para o campo político, Ronaldo argumenta que, antes da Lei 5.692/71, época na qual o aluno podia escolher para que modalidade de EM (científico, clássico ou normal) se encaminharia, o estudo podia ser mais prazeroso para este aluno visto que o curso escolhido estava mais de acordo com o seu perfil ou com suas aspirações profissionais.

Com posicionamento diferente, Gabriela acredita que um ensino de ciências de qualidade deve, obrigatoriamente, passar pela reflexão incansável e pela escuta dos alunos:

\footnotetext{
"no que os alunos estão interessados? Será que eu já parei para perguntar ao aluno o que ele mais gosta e por quê? O que ele gostaria de ver? O que ele não gostaria de ver? Será que eu dei espaço para ele traz̧er para a sala de aula alguma coisa?"
}

Para Gabriela, esse tipo de reflexão é o primeiro e grande passo para um ensino de ciências de qualidade. Segundo ela, sua prática é absolutamente norteada por todas as suas reflexões já que acredita ser fundamental "pensar sobre o que a gente fez, o que está fazendo e discutir, dialogar, tirar dali alguma coisa que vai melhorar a nossa prática".

César também responsabiliza o aluno pelos resultados alcançados: "vai depender também do quanto que cada um pôde tirar proveito e quis também tirar proveito". Entretanto, além da 
iniciativa individual do aluno, lembra que há um contexto social, marcado pela violência, por exemplo, que interfere nessa iniciativa.

Tatiana acredita que o aluno entra na escola entendendo-a como algo importante, ainda que isso não esteja atrelado aos conhecimentos a serem adquiridos, mas a fatores sociais, sendo a escola vista apenas como um meio para que ele consiga um diploma ou algum benefício social, como a bolsa família. Neste contexto, relata a falta de interesse dos alunos mesmo em aulas planejadas com atividades diferenciadas, como demonstrações de experimentos de física, levadas por estagiários universitários de prática de ensino. Em seu discurso, fica clara a impotência do pedagógico diante das dificuldades sociais, que acabam por gerar motivações distintas e incompatíveis: "O aluno não vê a escola como algo pra ele aprender, ele está ali porque ele quer o diploma, porque precisa da bolsa familia, porque precisa de coisas assim, entendeu?"

Gabriela reitera a fala dos outros professores, acrescentando, como mais um fator a fazer parte da complexidade da educação, o fato de o aluno chegar "sem a menor vontade de estar ali, sem a menor vontade de aprender qualquer coisa". Diz que procura diversificar a aula propondo diferentes metodologias de ensino, como experimentos e redações, mas os alunos, além de estranharem uma professora de física trabalhando com redação, também "não gostam de escrever, não gostam de matemática, não gostam de nada", e só se interessam se a tarefa "valer ponto", o que parece desanimá-la.

\section{Currículo: rígido, questionável, contextualizado}

Paulo acredita que, antecipando alguns conceitos da química para o $9^{\circ}$ ano do Ensino Fundamental (EF), poderá receber os alunos no $1^{\circ}$ ano do EM com mais base e mais conteúdo para "pisar no acelerador". Fica claro que Paulo assume o poder de alterar o currículo, no que diz respeito ao ritmo de ensino e à profundidade dos conteúdos, e que seu compromisso é com o cumprimento do currículo tal como é prescrito. A comparação estabelecida por Paulo entre o currículo que ele consegue implementar e o ensinado nos cursos pré-vestibulares pressupõe que o desempenho dos alunos no vestibular é tomado como padrão de qualidade.

Ao contrário de Paulo, para Júlio "a gente tem que ensinar ciência para aquelas pessoas que não são cientificas". Este professor ilustra seu pensamento com sua prática em uma escola prisional, mas o estende também à escola privada. A forma como concebe o ensino de ciências leva-o a se preocupar em propor alternativas à simples formação técnica, questionando-se: "que conteúdo que eu tenho que aplicar? Como é que eu tenho que levar essa matéria? O quê que eu tenho que fazer??' Júlio se posiciona criticamente em relação ao currículo oficial de ciências e assume a responsabilidade de alterá-lo. O relato de sua prática, à qual se refere como alfabetização científica, inclui a leitura de "alguma coisa de ciências" e a apresentação do conteúdo através de experimentos. Sua proposta parece priorizar a motivação dos alunos para a aprendizagem. Entre seus objetivos, estaria também a desmistificação da ciência, já que sua representação é, em geral, negativa: "a gente chega com esse monstro, cara. Química? É uma coisa horrível. Física? Nem pensar. Matemática? Tá doido".

Júlio acredita que o papel do professor não seja só o de transmitir conteúdo, porque este pode ser obtido por outros meios, como a internet. Para ele é mais importante tornar o conteúdo mais acessível ao aluno e cativar seu interesse pela ciência, por meio de visitas a laboratórios didáticos da universidade: "traz pra cá, vamos mostrar um experimento, vamos mostrar alguma coisa diferente". Ao mencionar essa alternativa, Júlio deixa claro seu envolvimento em 
projetos escolares, em parceria com a universidade onde estava sendo realizado o grupo focal, e sua crença nesse tipo de iniciativa.

Júlio traz outro aspecto do currículo a ser considerado na qualidade do ensino de ciências: "as ciências deveriam se comunicar mais". Ele defende a interdisciplinaridade, contrapondo-a à lógica disciplinar e fragmentada do currículo. Refere-se à integração dos conteúdos e, indiretamente, critica o currículo tradicional, composto por disciplinas estanques que, na prática, não se comunicam. Paulo atribui a incapacidade dos alunos em relacionar os conteúdos das diferentes disciplinas à implantação, por um longo período, de um currículo fragmentário, onde os conteúdos são distribuídos em "gavetinhas", as disciplinas, que não se comunicam entre si. Também menciona a formação disciplinar dos professores.

Ronaldo se refere às ciências "como uma coisa à parte, para maluco ou coisa de gênio", ratificando uma representação do senso comum que mistifica e justifica uma superioridade do conhecimento científico em relação aos demais. Para ele, os alunos usam celulares, têm DVD e "não sabem que existe física por trás disso", deixando-se apenas impregnar pelos valores consumistas que a mídia passa. Ele afirma que os alunos usam as tecnologias no cotidiano sem relacioná-las com o conteúdo científico passado pela escola. Mostra-se pessimista em relação à atual situação do ensino e não vislumbra qualquer perspectiva: "tá tudo muito complicado, tá muito ruim, não sei nem aonde isso vai dar, não sei o que vai acontecer, é imprevisivel'.

Ana considera que o currículo é o principal elemento a ser revisto na busca por uma educação de qualidade. Para ela, ainda que todos os demais elementos estejam de acordo com este propósito, se o currículo não for modificado, os esforços do professor serão em vão, já que os alunos de hoje têm acesso a informações por outros meios, como a internet, capazes de despertar seu interesse e fazê-los aprender.

Para Fátima, o currículo do EM não prepara o aluno para a vida, não oferece uma formação geral satisfatória para o desenvolvimento pleno do homem nem para se engajar no mercado de trabalho. Esta professora faz uma crítica à pressão sofrida para o cumprimento do currículo que inviabiliza, por exemplo, que o professor explore os fatos ou assuntos do momento, relacionando o conteúdo da disciplina com a realidade do aluno ou com o que está na mídia. Para ela, a qualidade do ensino está relacionada à obtenção de competências básicas para a leitura do mundo real, quando o aluno for capaz de entender e confrontar suas experiências ao aprendizado em ciências. Fátima acredita que a qualidade foi atingida quando seu aluno, ao ouvir falar sobre gordura trans, por exemplo, for capaz de entender o que isso significa com base em seus conhecimentos prévios e, mais que isso, caso não compreenda, que esteja apto a buscar as informações necessárias.

Já em relação ao ensino técnico, Fátima assume que é papel do professor exigir o domínio de determinados conteúdos científicos, e afirma "no men caso, em particular, que sou professora de Ensino Técnico, eu não posso botar um técnico no mercado, que não saiba algumas coisas". Nesse caso, o mundo produtivo e do trabalho são determinantes no que deve ser ensinado, o que não precisaria ocorrer no EM propedêutico.

Na sua prática com alunos do EJA do curso técnico de manutenção e instalação de computadores, Fátima aplica outra metodologia, baseando-se nas experiências dos próprios alunos e esforçando-se para que entendam sua realidade. Por isso, Fátima se detém em apenas alguns conceitos químicos que julga fundamentais, como o de átomo, para garantir uma base a outros conteúdos, desconsiderando os que julga irrelevantes para esses alunos. Fátima refor- 
ça, assim, a existência de duas escolas socialmente determinadas, o que obriga o professor a trabalhar de maneiras diferentes e oferecer conhecimentos de duas categorias, afirmando que, com os alunos do curso técnico, "é conhecimento por conhecimento", e, com os alunos do EJA, os conteúdos abordados seriam ligados às suas vivências diárias.

Marcelo, utilizando-se da justificativa de trabalhar numa escola pública estadual, diz que não tem o compromisso de seguir o currículo, no sentido de preparar seus alunos para o vestibular: "como professor do Estado eu me liberto disso". César julga ter autonomia relativa sobre o currículo, podendo escolher os conteúdos mais importantes para aprofundar ou alterar a sua ordem, embora alguns temas ele não possa deixar de ensinar. Em sua experiência no PEJA, César valoriza a socialização do indivíduo enquanto finalidade da educação neste segmento, mesmo quando não há apropriação do conteúdo. Interpelado por Ronaldo, que generaliza esta finalidade, considerando-a como o papel da escola, César percebe a possibilidade de uma escola dividida, que serviria de forma diferente à elite, que tem condições (de tempo e financeiras) de se apropriar do conteúdo, e à classe operária (sem o tempo necessário para estudar).

Na continuidade do seu discurso, percebe-se que a concepção de César é, sem dúvida, a de considerar como qualidade o acesso ao Ensino Superior, quando ele afirma que:

\begin{abstract}
"então, esse é que é o ponto, de ter o cuidado pra você, de repente, naquela onda de tudo pelo social, acabar havendo duas escolas: uma escola para formar operários e a escola que vai ser o centro de saber que vai formar os doutores, que vão continuar a elite manipulando a estrutura".
\end{abstract}

\title{
Métodos: renovação, tecnologias
}

Para Fátima, nem a escola nem as aulas de hoje podem ser como as de trinta anos atrás, porque a velocidade e o acesso às informações é muito mais rápido com o advento das TIC. Ela argumenta que nós, professores, não nos adaptamos a esta realidade e continuamos a dar aulas sem considerar as novas possibilidades das TIC para uma prática pedagógica mais próxima da realidade dos alunos. Fátima relata, também, que consegue motivar os alunos nas aulas de química por que dispõe de laboratórios em sua escola, o que permite práticas de ensino motivadoras.

Júlio concorda com Fátima no sentido de que os professores devem apoderar-se das ferramentas e da linguagem das TIC para realizar experimentos e responder questões propostas no ciberespaço que caracterizam mudanças. Ele aponta a necessidade da formação do professor a fim de que consiga apropriar-se destas ferramentas, ou seja, valoriza a necessidade de buscar alternativas metodológicas que se aproximem mais da realidade dos alunos, como o uso de blogs e de vídeos do YouTube na educação.

Segundo Júlio, ainda ensinamos como há trinta anos e é preciso "mudar alguma coisa". Ele parece acreditar, como Fátima, que acrescentar novas ferramentas no modo de ensinar seja suficiente para concretizar essa mudança e, assim, desloca o foco para os recursos tecnológicos como se estes pudessem promover, por si sós, uma mudança paradigmática na qualidade do ensino. Entretanto, ao queixar-se da desatualização do professor com relação às TIC, afirma que o conteúdo ensinado deve mudar, sem dar pistas de como isso poderia acontecer, por meio de políticas curriculares ou da ação do professor. 
César entende que é positivo o uso das TIC e alerta para o descaso dos professores e das escolas em relação às mudanças tecnológicas presentes na realidade do aluno. Sugere como alternativa que, em meio ao acesso rápido de informações disponíveis aos alunos, os professores revejam suas abordagens em sala de aula e encontrem "uma nova maneira de trabalhar", que se entende como o uso das TIC, para motivá-los. Suas considerações enfatizam o anacronismo em que se encontra essa escola que "continua do mesmo jeito que era, na estrutura, espaço físico e tudo o mais, até na grade curricular". César vê de maneira negativa o pouco progresso apresentado pela escola nos últimos anos, tanto no que se refere aos fatores estruturais e sociais quanto às mudanças de natureza pedagógica.

Fátima valoriza o trabalho de discussão com os alunos da "informação truncada que a mídia dả'. Dessa maneira, leva-os a aprenderem a partir dos equívocos relativos ao conteúdo científico divulgados pelos meios de comunicação, mas, por outro lado, ressente-se da falta de infraestrutura da escola para realizar este tipo de trabalho.

Segundo Ana, as aulas de "cuspe e giz" são um dos fatores que impedem um ensino de qualidade. Referindo-se à chegada de computadores às escolas e a distribuição de laptops para os professores, defende a ideia de que a inserção das TIC no ensino pode obrigar os professores a reverem suas práticas e a ministrarem aulas mais interessantes para os alunos. Em contrapartida, esta professora denuncia os entraves administrativos impostos pela escola e a falta de investimento em infraestrutura como obstáculos à melhoria da qualidade do ensino.

\section{Trabalho docente: comprometimento e frustrações}

César enfatiza que uma das formas de melhorar a qualidade do ensino é por meio do uso de novas técnicas por parte do professor. Também se refere à questão da remuneração e da necessidade de ter mais de um emprego como aspectos que interferem na qualidade do ensino.

Comparando sua experiência debutante à frente de uma turma ao relato de Ana que, apesar de muitos anos de magistério, mostra-se angustiada, Marcelo desabafa: "aí, eu boto na balança, o cara que tá em formação e o professor que tá há quinæ̌e, vinte anos no mercado. Os dois estão na mesma angústia, por mais que tenha quinze anos de experiência, ele está perdido também nessa sopa de angústia". Mas Ana afirma que "a angústia não é de todos", recriminando a postura daqueles que, sob a pressão do sistema, assumem a atitude de "deixar para lá".

Tatiana problematiza a atitude docente frente à aprendizagem dos alunos. Uma possibilidade é o professor considerar que o problema é do aluno e continuar a ensinar o conteúdo previsto no currículo, outra é quando o professor assume para si a responsabilidade de lidar com as limitações dos alunos ("o problema é nosso!"), sob pena de acabar com qualquer perspectiva que eles tenham dentro do EM. Ao considerar esta discussão como "muito mais ampla", a professora parece situar as origens dos problemas de aprendizagem desses alunos para além do âmbito pedagógico, atribuindo-os a fatores socioculturais e políticos. Ilustrando o que valoriza, relata sua prática de comprometimento com a aprendizagem enfatizando que o aluno tem de saber as quatro operações matemáticas e "vai sair sabendo, até aquele pior aluno que falou que não sabe nada, que pode não ser um expert, mas vai saber as operações". Para ela, a qualidade é atingida se seu aluno consegue transformar-se a partir de suas intervenções: "não pode sair do mesmo jeito que entrou". 
Ana relata que, assim como Tatiana, não consegue simplesmente entrar em sala de aula e ignorar as dificuldades cognitivas dos alunos. Valoriza o comprometimento do professor com a formação daqueles estudantes que, no seu caso, são futuros professores das primeiras séries do EF. Ela deixa claro seu desespero quando se refere ao despreparo dos alunos que saem do curso de formação de professores, vão para o estágio e voltam: "Professora, eu tinha uma dúvida, o animal tal é mamifero?' Eu digo 'Ai meu Deus, o que você falou pra criancinha?' Já me dá aquela dor no coração. "O que você falou?"

\section{O espaço escolar}

Ao invés de atribuir o fracasso escolar às deficiências dos alunos, Tatiana ressalta a importância do papel da escola na sociedade para que a esta possa cobrar qualidade: "a escola tem que ser encarada como um órgão que pode transformar a vida dele, porque se não é só bolsa-escola, auxíliogás, não vai fazerer a menor diferença". Esta professora questiona a escola vinculada apenas a medidas assistencialistas de caráter populista as quais, para ela, não contribuem para a qualidade do ensino.

Ana demonstra insatisfação e angústia ao relatar o sucateamento das escolas: "é laboratório que não pode usar nunca, a sala de informática que também não pode, a biblioteca, só se tiver um professor, que nunca tem", enfim, problemas que ela reconhece que não podem ser resolvidos apenas pela ação do professor e impedem a educação de qualidade. César também se ressente do sucateamento e abandono das escolas afirmando que estão até piores porque não foram consertadas e "estão caindo aos pedaços".

\section{Políticas educacionais anteriores à LDB}

César e Ronaldo acusam a Lei 5.692/71 pela decadência da educação. Dentre os participantes do grupo focal, eles são os mais velhos e com mais tempo de magistério e, talvez por isso, parecem falar dessa decadência como testemunhas do processo. César refere-se à mudança proporcionada pela referida lei, que diluiu o Ensino Secundário (antes dividido em científico, clássico, normal e técnico) em cursos profissionalizantes. Segundo ele, isso não atendeu aos interesses dos alunos, que, quando tinham "afinidade" com a matemática ou a física, escolhiam o científico. Hoje, os alunos são abarrotados de conteúdos que não atendem às suas necessidades tendo em vista a profissão que vislumbram.

Ronaldo atribui o problema atual de aprendizagem de ciências à "famigerada lei 5692", que instituiu a formação geral (além da profissionalizante), colapsando os antigos "clássico" e "científico". Nos dias de hoje, os adolescentes, muitas vezes, têm de aprender matérias com as quais têm pouca afinidade (e, por isso, não aprendem com prazer) e estariam distantes de uma provável escolha profissional.

César considera que a política educacional instaurada a partir da Lei 5.692/71 teria sido promotora do "enfoque natural do ensino", o que contrapõe com o contexto político educacional atual, caracterizado pela obrigatoriedade da conclusão do EM para atuação no mercado de trabalho. Nesse contexto, o aluno é "obrigado a fazer um curso, pra ter um diploma, pra garantir 
trabalho, sem ter, muitas vezes, realmente condição de estar al". O enfoque dito "natural" já selecionava, antes do ingresso no EM, o público capaz e, segundo César, que tinha "afinidade" individual com o currículo proposto no EM. Ao considerar a escolha entre a universidade e os cursos técnicos como uma questão individual, César parece não enxergar a seletividade embutida no sistema anterior.

\section{Políticas educacionais recentes}

Ronaldo trabalha em um colégio estadual bem conceituado no Méier no qual ele estudou. Mostra-se decepcionado com as políticas educacionais do Estado e do Município que, para ele, contribuíram para a decadência do ensino público. Queixa-se do baixo nível de conhecimentos dos alunos no EM, responsabilizando a política educacional do Município do Rio de Janeiro por produzir analfabetos, que terminam o $9^{\circ}$ ano sem saber preencher um cabeçalho. Chama a atenção, sobretudo, para a eliminação do concurso para o ingresso no EM, que levou, segundo ele, à entrada de alunos dos mais diferentes níveis de aprendizagem e à queda exponencial da qualidade. O sentido de qualidade de Ronaldo está, assim, atrelado à seletividade dos alunos.

Marcelo, de início, defende que a progressão continuada (escolarização por ciclos de aprendizagem, com retenção apenas no final de cada ciclo) foi "uma proposta linda" instituída pelo Município e acredita que essa medida foi "vendida pela mídia, pelos sindicatos dos professores de forma distorcida, ou seja, como aprovação automática", proposta no fim da gestão do prefeito Cesar Maia, na qual o aluno passaria direto em qualquer série. Ele se opõe à ideia de o aluno ser reprovado, respaldando-se em pesquisas como Saeb e Saerj, que apontam para resultados piores para alunos que permanecem há mais de oito anos no EF, sem, no entanto, problematizar as avaliações oficiais.

Fátima concorda que foi um "bonito projeto", porém analisa criticamente a implementação das políticas públicas e conclui que o "problema não está na reprovação, mas nos mecanismos de recuperação desse aluno", pois não há infraestrutura para realizá-lo. Traz para o cenário a formação docente e denuncia que grande parte dos professores novos "estão chegando com uma formação exatamente muito próxima da que os alunos estão tendo hoje”. Para ela, se por um lado a reprovação, nas condições em que é realizada, não garante a aprendizagem, por outro não adianta aproválos automaticamente, visto que concluirão o nível superior como professores malformados, mantendo um ciclo contínuo de má-formação. Fátima aponta, como aspectos que impactariam a qualidade da educação, a existência de mecanismos de recuperação dos alunos e infraestrutura da escola para atender à demanda de alunos com dificuldades de aprendizagem e a formação adequada de professores.

Ronaldo é favorável à reprovação, enquanto instrumento legítimo de seleção da escola, e ao jubilamento, enquanto sanção aos alunos reprovados seguidamente, como acontecia anteriormente: "jubilava-se o aluno e ninguém morria por causa disso". Ao atribuir, à política municipal, o fracasso dos seus alunos no EM, Ronaldo transfere a responsabilidade pela qualidade do ensino exclusivamente para a esfera das políticas públicas.

Ronaldo e César também se queixam da pressão que os professores do Estado e do Município recebiam para "aliviarem a caneta vermelha", facilitando a aprovação dos alunos mes- 
mo antes da legislação que estabeleceu a progressão automática. Acerca dos índices de reprovação relacionados ao elevado número de faltas dos alunos, Ana ironiza as políticas públicas ao comentar que, hoje, os alunos podem tudo, menos faltar, para não perderem a bolsa família. Seu interesse em frequentar a escola, para Ana, reduz-se à garantia de recebimento dos benefícios concedidos por um programa que favorece o acesso aos direitos sociais básicos, promove a inclusão social e estabelece, como uma das condições, o cumprimento da obrigatoriedade escolar.

Para César, políticas educacionais que investem em recursos como "datashow e computadores" são importantes pois favorecem o acesso rápido à informação em sala de aula, tal qual o aluno dispõe fora da escola, e, consequentemente, o mantém mais interessado. Entretanto, ressalta que, muitas vezes, a escola não dispõe do espaço físico adequado para abrigar esses equipamentos. Segundo ele, alguns anos de má gestão resultaram no sucateamento e abandono das escolas e na falta de recursos para incrementar as aulas, o que culminou em aulas de "cuspe e giz" e impossibilidade de competir com a mídia apresentada fora da escola.

Ronaldo relaciona a qualidade do ensino "em primeiro lugar, à valorização do profissional" e denuncia a falta de interesse da administração pública em ter um profissional bem remunerado nas escolas públicas do Ensino Básico. Critica a atual gestão do governo estadual quando distribui (em regime de comodato) laptops aos professores como política de valorização profissional ou de instrumentalização para a modernização da educação.

Paulo justifica que, para se alcançar um ensino de qualidade, é preciso rever a questão da remuneração do professor, "porque você, pra ser professor no Brasil, você tem que correr lá, aqui, acolá, porque num lugar só não dá, manter teu padrão de vida e o que mais me pesa é justamente isso, a falta de tempo de organizar melhor [...] o meu planejamento, o que eu vou colocar".

César compara o conteúdo do aluno do $1^{\circ}$ segmento do EF de trinta anos atrás com o do aluno do $2^{\circ}$ segmento do EF nos dias de hoje, e conclui que seus repertórios de conteúdos são semelhantes, o que deixa evidente a queda da qualidade. Ele atribui essa decadência à obrigatoriedade escolar, que fez com que as escolas recebessem alunos, que antes não frequentavam a escola, para contribuir com a renda familiar. Assim, César atribui à universalidade do EM, que configura o contexto educacional e social atual, a dificuldade de aprendizagem de alguns alunos que anteriormente não ingressariam neste nível de ensino. Este professor ironiza o sistema educacional frente às exigências colocadas pelo mercado de trabalho, e quanto essas exigências nem sempre correspondem a uma real necessidade da formação de nível médio. Relata um caso, quando encontra um ex-aluno na profissão de frentista, a quem teria perguntado se o mesmo aproveitara bem a química orgânica, os hidrocarbonetos, abastecendo os tanques dos carros. Esse enunciado aponta para as contradições sociais que permeiam o sistema educacional e sua impotência em promover avanços sociais.

\section{Tensões entre as perspectivas docentes}

Para defenderem suas perspectivas, os professores constroem seus discursos a partir do diálogo com diversas linguagens sociais. A linguagem social que parece dominante, quando se referem aos problemas curriculares, de aprendizagem dos alunos e à prática pedagógica, é o discurso que circula na sua escola, no grupo social que compartilha a atividade de ensinar 
naquele determinado contexto educacional. Diferentes realidades educacionais moldariam as linguagens sociais dos professores e, consequentemente, suas concepções sobre o currículo, finalidades da educação e sociedade. Embora possa haver consensos, essa diferença se desdobra, em geral, em tensões entre as perspectivas.

Assim, foi possível observar que Paulo, professor de uma escola privada, questiona menos o currículo e vê a qualidade do seu ensino como sinônimo de melhor performance do aluno no vestibular. Este professor se exime de uma reflexão mais profunda que, de fato, poderia levá-lo a questionar currículo, avaliação, políticas educacionais, vestibular etc. Fátima diferencia sua voz pelo pertencimento a uma escola técnica pública, que considera superior em termos de qualidade, devido à seleta clientela que recruta. Já, entre os professores de escolas públicas, percebemos diferentes vozes que nos pareceram diferenciadas pelo tempo de experiência profissional.

A falta de qualidade do ensino de ciências está ligada, para a maioria, ao anacronismo do currículo e da escola de uma maneira geral, frente ao cotidiano dos alunos, sendo que o fator que mais o torna claro é a presença avassaladora da tecnologia no ambiente social. Neste ponto, foi possível perceber uma tensão entre os professores que acreditam que tecnologizar o ensino de ciências o salvaria desse anacronismo e outros que afirmam que apenas isso não basta. Neste sentido, a defesa da educação científica com uso das tecnologias foi mais frequente, mas também esteve presente a ideia de se abordarem os artefatos tecnológicos como contexto para a aprendizagem, assim como prescrevem os PCNEM.

O discurso sobre a questão curricular também foi tensionado entre seguir o currículo visando à seleção do vestibular ou moldar o currículo para atingir outros objetivos. Neste ponto, houve a preocupação em favorecer a aprendizagem de ciências, mas também a socialização dos alunos e a construção de um conhecimento útil à sua realidade. Este último foi polêmico entre os professores, pois viria a conformar duas escolas socialmente determinadas. Essa discussão esbarra no debate entre a qualidade para todos ou a seleção de um grupo tecnicamente preparado para o Ensino Superior.

Ao assumir que sempre se questiona e que não possui uma fórmula para o ensino de química, Júlio mostra-se comprometido com um ensino de ciências de qualidade que se afasta do cumprimento de um mesmo currículo ou metodologia de ensino para todos os alunos, independentemente do contexto. Já Marcelo não segue o currículo porque, para ele, os alunos da escola pública não conseguem ou não podem aspirar ao Ensino Superior, visto que a qualidade do ensino que recebem não lhes permite tal acesso e que a meta final desses alunos é o mercado de trabalho.

Com relação ao trabalho docente, percebemos uma tensão entre a prática que endossa a ausência de qualidade, caracterizada pela falta de mobilização e comprometimento, e outra que se coloca como militante pela qualidade, apesar da escola, do salário, das condições de trabalho. Diante da situação de sucateamento do sistema educacional, relatada por diversos professores do grupo, os professores se debatem entre a impotência para resolver os problemas que se apresentam e a atitude que assumem para si quanto à necessidade de mudança. Estes acreditam que o nível de comprometimento do professor com a aprendizagem dos alunos, ao refletirem sobre sua prática docente e se utilizando de novas metodologias, pode garantir a qualidade do ensino. Essa visão atribui, ao indivíduo, o alcance da qualidade, sem reconhecer que um real interesse do poder público em investir na qualificação e remuneração 
dos profissionais da educação possibilitaria o comprometimento de um número expressivo de professores.

Para Ronaldo e César, que têm mais tempo de magistério, o sucesso seria atingido pelo interesse do aluno, estimulado pelo ensino anterior à Lei 5.692/71. Ao dialogarem com o discurso oficial daquela época, em que a maioria dos alunos pertencia à classe média e, em função disso, trazia capital cultural diferente dos alunos de hoje, esses professores não reconhecem a seletividade que estava embutida no sistema educacional e, por isso, são capazes de valorizá-lo. Ao defender o jubilamento como prática que poderia contribuir para a qualidade do ensino, Ronaldo parece aceitar a exclusão como resultado educacional, sem problematizar o contexto sociocultural e o sistema meritocrático em que este tipo de prática se insere.

Ao mesmo tempo, Ronaldo e César denunciam o recrutamento de estudantes de todos os níveis e interesses como a causa da falta de qualidade do ensino atual, sem perceber que o sistema deveria dar as condições para lidar com este público diversificado e muito mais amplo. Ana também culpabiliza a inclusão de alunos, antes excluídos, pela queda da qualidade do ensino, não reconhecendo, nessa inclusão, um avanço da qualidade da educação no que diz respeito à democratização das oportunidades de acesso escolar e de possível ascensão social.

O fracasso na aprendizagem de ciências se daria, segundo as diferentes vozes dos professores, pela falta de base, de interesse ou de prazer. Estas questões, envolvidas na complexidade do ato educativo e originadas no contexto sociocultural mais amplo, precisam ser aprofundadas. $\mathrm{O}$ desinteresse dos jovens pelas ciências naturais tem assumido dimensões preocupantes em vários países. Para Fourez (2003), os educandos não se interessam por estudos científicos impostos pelo sistema educacional - que visam a interesses apenas da comunidade científica ou do mundo industrializado - porque os percebem como desarticulados dos problemas de sua realidade. Além do desinteresse, Lemke (2006) aponta a exclusão de grande parte da população, produzida pelo ensino de ciências, por ter sido, ao longo das últimas décadas, impulsionado pelo interesse político na formação da força de trabalho técnica e cientificamente preparada.

Não percebemos uma preocupação epistemológica, no sentido da necessidade de se abordar a prática científica com os alunos. A visão de ciência esboçada pelos professores revelou uma caricatura de algo muito difícil, a ser alcançado por poucos. Caberia aqui um aprofundamento, por meio de estudos futuros, no sentido de se compreenderem as raízes dessas representações. Um ponto de partida seria considerar o alerta de Arroyo (1988) em relação ao ensino de ciências, forjado pela Lei 5.692/71, dotado de certo mistério comum às ciências exatas, saber superior às demais ciências, o que produziria também sua inquestionabilidade.

Júlio e Gabriela dialogam explicitamente com discursos oriundos da pesquisa na área de EC, que provavelmente circularam no contexto de formação continuada de ambos. Os enunciados de Gabriela ressaltam a reflexão incansável por parte do professor, ecoando as ideias de Donald Schön usadas na pesquisa educacional. Júlio se inspira no conceito de alfabetização científica (FOUREZ, 1999; SANTOS, 2007b), conceito esse que vem sendo objeto de vários pesquisadores da área.

A política de aprovação automática do município do Rio de Janeiro, vigente até o ano passado, foi muito mencionada e criticada. A política do governo do Estado do Rio de Janeiro de distribuição de laptops aos professores também foi mencionada e igualmente criticada. A perspectiva dos professores em relação a estas políticas pode ser considerada um ponto posi- 
Rezende, F. et al.

tivo na medida em que demonstraram um posicionamento crítico em relação à associação governamental entre elas e a qualidade do ensino.

Embora os professores não tenham mencionado explicitamente os PCNEM, foi possível perceber que os conceitos fundamentais que alicerçam o ensino de ciências (contextualização, interdisciplinaridade e competências) estão presentes nos enunciados de Paulo, Júlio, Gabriela, Fátima e Tatiana. Relacionar os conteúdos com o cotidiano dos alunos, com a tecnologia ou a atualidade passou a ser um objetivo relevante para o professor de ciências. Entretanto, não foram percebidos questionamentos em relação a esse conceito que implicassem diferentes abordagens do mesmo, como, por exemplo, a ideia de ir além do entendimento de um fenômeno presente na realidade, abordando suas dimensões sociais, políticas e culturais, como sugere Santos (2007a).

\section{Considerações finais}

Um resultado da análise pode ser percebido a partir da recorrência do sentido da falta de qualidade atribuída à educação pública e privada e, em particular, ao ensino de ciências. Esta falta de qualidade foi atribuída a problemas pedagógicos e políticos. Por meio da denúncia da falta de qualidade, o discurso dos professores deixa pistas sobre o que seria a suposta qualidade.

Em geral, os professores investigados se manifestaram sobre os elementos pedagógicos da EC se utilizando da linguagem social típica de sua vivência escolar, em enunciados apartados daqueles nos quais se referiam aos aspectos políticos, construídos em diálogo com a legislação educacional. Percebemos que, embora os professores reconheçam relações entre a educação e a esfera política, não parecem reconhecer o caráter político inerente ao ato educativo, ou à educação científica em particular, manifestado em suas finalidades, proposta curricular, metodologias etc. Também não percebemos a preocupação com sua implicação na reprodução ou transformação da sociedade.

A tensão entre seguir o currículo das disciplinas científicas, tal como previsto pela legislação ou pela escola, e alterá-lo de acordo com a realidade onde está inserido ou com as necessidades dos alunos permeou o discurso dos professores pesquisados, mesmo que de modo diferenciado entre eles. Enquanto alguns apontaram o acesso ao nível Superior de ensino como meta educacional a ser alcançada, outros defenderam a contextualização e as atividades diferenciadas como atributos positivos e motivadores do processo ensino-aprendizagem. Os primeiros entendem estas práticas como algo negativo que pode conduzir à queda do nível da qualidade do ensino, dada a enorme quantidade de conteúdos a serem abordados nas disciplinas científicas.

A maioria dos professores apontou a utilização das TIC como alternativa ao anacronismo do ensino de ciências, acreditando que as tecnologias podem inserir, no ambiente escolar, o mundo vivenciado pelos alunos em suas atividades fora da escola. No entanto, há alguns professores que, embora entendam a tecnologia como algo essencial, visto que esta é uma constante na realidade dos alunos, apostam que apenas a utilização das TIC não dará conta de garantir um ensino de ciências de qualidade. 
Enquanto alguns professores atribuíram o problema da qualidade da educação a questões relacionadas às más condições de trabalho, à desvalorização docente, aos baixos salários e ao sucateamento do sistema educacional como um todo, na fala de outros, ainda que inseridos nesta mesma realidade, percebemos a ilusão de que a qualidade pode ser atingida por iniciativa individual.

Foi possível notar, no discurso político desses professores, a dicotomia qualidade versus quantidade, envolvida na questão da qualidade da educação. Enquanto alguns permanecem com o discurso conservador (BEISIEGEL, 2006) que privilegia a qualidade para poucos em detrimento da democratização do acesso à escolaridade, outros, reconhecendo que a massificação desse acesso alterou num primeiro momento a qualidade do ensino, apostam na qualidade da educação como direito de todos.

Não conseguimos perceber diferenças entre os sentidos de qualidade atribuídos pelos professores de diferentes comunidades disciplinares. Para tal, é necessário aprofundar esta discussão em futuros trabalhos. Em contrapartida, diferentes sentidos de qualidade percebidos pareceram estar associados aos diferentes contextos profissionais de professores de escolas públicas, privadas e técnicas. Entre os professores de escolas públicas, as perspectivas nos pareceram diferenciadas pelo tempo de experiência profissional.

Apesar das diferenças entre os contextos educacionais e entre as linguagens sociais com as quais os professores dialogaram, podemos apontar um sentido negativo de qualidade, atribuído por todos eles, à educação científica. Concluímos que a complexidade da nossa sociedade incide diretamente sobre todas as tensões e perspectivas identificadas, se desdobrando nos sentidos que os professores atribuem à educação, ao ensino de ciências e a todos os elementos que o conformam. Ao lado de outros problemas sociais, os problemas da educação se agravam em meio ao descaso com que ela ainda é tratada pelos que poderiam e deveriam agir em prol da melhoria de sua qualidade.

\section{Referências}

ARROYO, M. G. A função social do ensino de ciências. Em aberto, Brasília, v. 7, n. 40, p. 3-11, 1988.

BAKHTIN, M. Estética da criação verbal. São Paulo: Martins Fontes, 2003.

Marxismo e filosofia da linguagem. São Paulo: Hucitec, 2004.

BANET, E. Finalidades de la educación científica en secundaria: opinión del profesorado sobre la situación actual. Enseñanza de las Ciencias, Barcelona, v. 25, n. 1, p. 5-20, 2007.

BEISIEGEL, C. R. A qualidade do ensino na escola pública. Brasília: Líber Livro, 2006. BRASIL. Ministério da Educação. Parâmetros curriculares nacionais. Brasília: MEC/ SEM, 1998. 
Rezende, F. et al.

CHASSOT, A. Fazendo uma oposição ao presenteísmo com o ensino da filosofia da ciência e da história da ciência. Episteme, Porto Alegre, v. 3, n. 7, p. 97-107, 1998.

FOUREZ, G. Alfabetización científica y tecnológica: acerca de las finalidades de la enseñanza de las ciencias. Buenos Aires: Ediciones Colihue, 1999.

Crise no ensino de ciências. Investigações em Ensino de Ciências, Porto Alegre, v. 8, n. 2, p. 109-123, 2003.

FREITAS, M. T. A. Vygotsky \& Bakhtin: psicologia e educação: um intertexto. 4. ed. São Paulo: Ática, 2003.

LEMKE, J. L. Investigar para el futuro de la educación científica: nuevas formas de aprender, nuevas formas de vivir. Enseñanza de las Ciencias, Barcelona, v. 24, n. 1, p. 5-12, 2006.

MOREIRA, A. F. B.; KRAMER, S. Contemporaneidade, educação e tecnologia. Educação e Sociedade, Campinas, v. 28, n. 100, p. 1037-1057, 2007.

REZENDE, F.; OSTERMANN, F. A prática do professor e a pesquisa em ensino de física: novos elementos para repensar essa relação. Caderno Brasileiro de Ensino de Física, Florianópolis, v. 22, n. 3, p. 316-337, 2005.

REZENDE, F.; OSTERMANN, F.; FERRAZ, G. Ensino-aprendizagem de física no ensino médio: o estado da arte da produção acadêmica no século XXI. Revista Brasileira de Ensino de Física, São Paulo, v. 31, n. 1, p. 1402.1-1402.8, 2009.

SANTOS, W. L. P. Contextualização no ensino de ciências por meio de temas CTS em uma perspectiva crítica. Ciência \& Ensino, Campinas, v. 1, n.esp., p. 126-152, 2007 a.

Educação científica na perspectiva de letramento como prática social: funções, princípios e desafios. Revista Brasileira de Educação, Rio de Janeiro, v. 12, n. 36, p. 474-549, 2007b.

SANTOS, W. L. P.; MORTIMER, E. F. Uma análise de pressupostos teóricos da abordagem C-T-S (Ciência-Tecnologia-Sociedade) no contexto da educação brasileira. EnsaioPesquisa em Educação em Ciências, Belo Horizonte, v. 2, n. 2, p. 1-23, 2002.

WERTSCH, J. V. Voces de la mente: un enfoque sociocultural para el estudio de la acción mediada. Traducción Adriana Silvestri. Madrid: Visor Distribuciones, 1993.

. La mente en acción. Argentina: Aique Grupo, 1999.

Artigo recebido em agosto de 2010 e aceito em fevereiro de 2011. 